Tohoku J. Exp. Med., 2009, 218, 229-239

\title{
Inequity in Dental Care Utilization in the Indonesian Population with a Self-Assessed Need for Dental Treatment
}

\author{
Diah Ayu Maharani ${ }^{1,2}$ \\ ${ }^{1}$ Health Care Economics, Graduate School of Medical and Dental Sciences, Tokyo Medical and Dental University, \\ Tokyo, Japan \\ ${ }^{2}$ Department of Preventive and Community Dentistry, Faculty of Dentistry University of Indonesia, Jakarta, \\ Indonesia
}

\begin{abstract}
Dental caries is one of the most prevalent infectious diseases in Indonesia. More than half of all cases are left untreated. This may be due to inequity in the use of dental care that is caused by economic and geographic barriers. Therefore, the objective of this study was to provide evidence of socioeconomicrelated inequality and horizontal inequity in dental care utilization among Indonesian adults who reported having had dental problems and to describe the sources of any identified inequality. We used secondary cross-sectional data from the Indonesian National Socio-Economic Survey 2004 and from the Indonesian Medical Council. Respondents included individuals at least 15 years old who reported having had dental care needs within a one-month recall period $(N=20,718)$. A concentration curve and a concentration index were employed to describe the extent of inequality. A horizontal inequity index was applied to identify inequity. A decomposition method was used to describe the sources of inequality. The concentration curve indicated a slightly pro-rich inequality in dental care utilization. The concentration index showed a significant concentration of dental care utilization among groups with higher socioeconomic status (SES). The horizontal inequity index illustrated higher unmet dental care needs among lower SES groups. Decomposition revealed that higher SES, urban Java Island residency, and insurance coverage were positively associated with the likelihood of dental care utilization. This study concludes that the expansion of health insurance, especially targeted at low SES groups, and a regionally equitable distribution of dentists may reduce economic and geographic barriers to dental care in the future. ——Dental care; Indonesia; inequality; horizontal inequity; decomposition.
\end{abstract}

Tohoku J. Exp. Med., 2009, 218 (3), 229-239. (C) 2009 Tohoku University Medical Press

Healthcare reform in Indonesia is becoming more important due to economic instability, which has limited access to healthcare. Access to dental care is also affected. Dental care requires more attention than it is currently receiving, since dental problems cause pain, result in impaired mastication, and affect quality of life. Moreover, the Indonesian Household Health Survey (SKRT) 2004 identified dental caries as one of the most prevalent infectious diseases. Of the population aged 15 years and above, $71.2 \%$ had caries, and $52.3 \%$ of cases were untreated.

Financial barriers to treatment are one of the reasons behind the low demand for professional dental care (Sudiono 2008). Insufficient health insurance coverage has ensured that the greater burden of dental health impairment falls on socio-economically disadvantaged populations. Community participation in health insurance, which included dental care (primary dental treatment; i.e., treatment for decayed teeth and tooth extraction), reached only $26.9 \%$ in the year 2004, including 7.0\% Askes (government employee insurance),
$2.5 \%$ Jamsostek (private sector employee insurance), $12.6 \%$ Kartu Sehat (insurance for the poor), and $4.8 \%$ other health insurance. Therefore, health care, including dental care, during that period were mostly financed from out-of-pocket payments by households (Hidayat et al. 2004; WHO 2005). If the ability to pay is a determinant of dental care utilization, then we conclude that individuals with equal needs, but with different abilities to pay, may not receive equal dental treatment.

Indonesia is the world's largest archipelago, consisting of 17,508 islands. It is also the world's fourth most populous country, with $217,072,346$ inhabitants as of the year 2004. However, the number of dentists is insufficient (Thabrany 2006). Data from the Indonesian Medical Council suggest that there are 17,252 registered dentists in the country, most of whom are located on Java Island. On average, every $12,582.45$ individuals were served by one dentist. In other words, only 2.4 dentists were available for every 30,000 individuals, which is the number that

Received April 27, 2009; revision accepted for publication May 28, 2009. doi:10.1620/tjem.218.229

Correspondence: Diah A. Maharani, D.D.S., Health Care Economics, Graduate School of Medical and Dental Sciences, Tokyo Medical and Dental University, 1-5-45 Yushima, Bunkyo-ku, Tokyo 113-8510, Japan.

e-mail: rani.hce@tmd.ac.jp or ranizaeni@yahoo.com 
Indonesian community health centers were to provide care for (Kristiansen and Santoso 2006). In addition to the shortage of dentists, we note that most low-income populations are situated in rural areas. These conditions might increase disparities in access to dental care among different socioeconomic status (SES) groups. Considering these economic and geographic facts, we might ask whether government dental health policy has achieved equity in dental care utilization to date.

The concept of inequity is understood in terms of unnecessary and avoidable differences, conveying a sense of unfairness and unjustness (Whitehead 1992). In addition, equity involves care being delivered based on need and requires that people in equal need of care be treated equally, irrespective of characteristics such as income and residence. In short, the term "inequity" has a moral and ethical dimension. On the other hand, the term inequality is dimensional and simply refers to the measurable quantity of differences and variations, without implying any moral judgments (Kawachi et al. 2002). Equality is merely the situation under which everyone receives the same amount of care (Braveman 2006).

The principle of health equity in Indonesia has been expressed in terms of its political philosophy. Increasing access for citizens to health services, including dental care in a manner irrespective of socio-economic status is one of the primary targets of the Indonesian Ministry of Health $(M O H)$ (Thabrany 2006). In addition, citizens' basic healthcare rights were specified in the amendments of 2000 and 2002 to the Indonesian 1945 Constitution to include the establishment of a national social security system and the provision of basic healthcare to all citizens (WHO 2005). Based on the above legal reforms, the government's task has been more clearly defined: to make healthcare a priority in the country's development and to provide healthcare equally to every citizen. However, it is difficult to make this policy operational without a clear picture of dental healthcare utilization. Moreover, our literature review found few recently published studies that described a high need for dental care in Indonesia (Morgan et al. 1992; Sudiono 2008). Therefore, the objective of this study was to provide evidence of socioeconomic-related inequality and horizontal inequity in dental care utilization among Indonesian adults who reported having had dental problems and to describe the sources of any identified inequality. The sources will be decomposed not only economically but also geographically.

\section{Data and Methods}

This study used secondary cross-sectional data from the Indonesian National Socio-Economic Survey (Susenas) 2004 and the Indonesian Medical Council. Susenas is a nationally representative survey that is carried out annually by the Indonesian National Board of Statistics (BPS). It uses cluster sampling, sorted geographically by province, and it includes demographics, living standards data and data on actual dental care utilization. The total sample size of Susenas in
2004 was 1,052,091 individuals of all ages, covering 257,906 households in 30 provinces (BPS 2002). The Indonesian Medical Council records data on the number of dentists in each province in Indonesia. This study included only individuals aged 15 years and older who reported having had dental problems within a one-month recall period. After data cleaning, the number of adult respondents was 730,832 , excluding children aged less than 15 years. Out of those, the number of adult respondents who reported having had dental problems was 20,718; those individuals were the subjects of this study, with the assumption that their dental problems had impacted daily living. Therefore, they should be prioritized for dental care regardless of their SES. The data were weighted to ensure that the sample was representative of the Indonesian adult population by adjusting for the complex sample design of the Susenas. All of our statistical analyses were performed using Stata version 9. We used suitable commands to account for the sampling weights and the complex survey data. A significance level of 0.05 was used throughout to denote statistical significance. BPS and the Indonesian Medical Council approved the analysis of their data in the context of this study.

In developing countries such as Indonesia, formal employment is less common. Many households have multiple and continually changing sources of income, and while consumption continues over time, income is only received intermittently. This study used total household consumption to measure the standard of living and to rank and categorize individuals into quintiles, ranging from the poorest (1st quintile) to the richest (5th quintile). It is expected that household consumption should ideally be more directly related to the standard of living. To adjust for size and age structures of households, total household consumption was divided by the adult-equivalence scale. Consistent with previous studies (Deaton 1997; Somkotra and Detsomboonrat 2008), it was defined as $e_{h}=\left(A_{h}+\alpha K_{h}\right)^{\theta}$, where $A_{h}$ is the number of adults in household $h$ and $K_{h}$ is the number of children (0-14 years). Children typically consume less than adults, so counting children as adults may overestimate the living standards of households with children. For developing countries such as Indonesia, empirical studies recommend that a child aged under 15 should be modeled as costing roughly half of what an adult costs $(\alpha=0.5)$ (O'Donnell et al. 2007; Yiengprugsawan et al. 2007). In addition, household members can share certain types of goods and services, making these consumables cheaper in households of two or more persons than in one-person households. Therefore, based on previous studies, the household economy of scale $(\theta)$ was estimated to equal 0.75 for any household with more than one member (Deaton 1997; O'Donnell et al. 2007; Yiengprugsawan et al. 2007).

The methods used in this study were conceptually identical to those proposed in previous studies (Goddard and Smith 2001; Wagstaff et al. 2003; Van Doorslaer and Jones 2003; Lu et al. 2007; O'Donnell et al. 2007). The concentration curve was used to describe inequality, and the concentration index $(C)$ was used to measure relative inequality in dental care utilization as related to living standards. For weighted data, $C$ can be conveniently computed as (Lu et al. 2007; Van Doorslaer et al. 2008):

$$
\frac{2 \sigma_{R}^{2}}{\bar{y}_{i}} \quad y_{i}=\alpha+\gamma R_{i}+\varepsilon_{i}
$$

Actual dental care utilization is denoted by $y_{i}$, and $\bar{y}_{i}$ is its weighted mean. In our study, $y_{i}$ was binary, indicating whether a respondent had actually received dental care within a one-month 
recall period. $R_{i}$ is the weighted relative fractional rank of the $i$ th individual in the living standard distribution. $R_{i}=i / N$, with $i=1$ for the poorest and $i=N$ for the richest. $N$ is the sample size. $\sigma^{2}{ }_{R}$ is the weighted variance of $R_{i}$. The ordinary least square (OLS) estimate of $\gamma$ is equal to the $C$ associated with actual dental care utilization $\left(C_{M}\right)$.

In addition, to determine how the actual distribution of dental care utilization matched the distribution of need for dental care, we assessed the horizontal inequity index $(H I)$. In our study, $H I$ was in fact used as the yardstick for assessing inequity in dental care utilization in Indonesia. To compute $H I$, we employed a two-step approach (Nguyen and Häkkinen 2004). In the first step, we predicted the expected need for dental care utilization $\left(\hat{y}_{i}\right)$ based on actual dental care utilization $\left(y_{i}\right)$. The value of $\hat{y}_{i}$ was obtained by regressing $y_{i}$ on a set of need and non-need determinants $\left(x_{k}\right)$. These determinants $\mathrm{w}$ ere selected based on previous empirical analysis of dental care utilization (Nguyen and Häkkinen 2004; Somkotra and Detsomboonrat 2008). Variables such as age and gender were used as proxies for need (O'Donnell et al. 2007). Indirect standardization using a nonlinear logistic regression was applied to standardize dental care needs $\left(\hat{y}_{i}^{I S}\right)$. The aim of standardization was to determine what the distribution of dental care utilization would look like in the absence of differences in the distribution of certain standardized need determinants, here age and gender (Van Doorslaer et al. 2000; Ohkusa and Honda 2003; Somkotra and Detsomboonrat 2008). The age and gender combination used can be seen in Table 1. The non-need determinants are defined as other explanatory variables that correlate with dental care utilization (Somkotra and Detsomboonrat 2008). Based on Indonesia's demographic characteristics and guidance from other empirical work (Nguyen and Häkkinen 2004), several non-need variables were included: (1) living standards in quintiles; (2) educational attainment, distinguished by no formal education, primary, secondary and higher education; (3) work status, categorized as agriculture/fishery, selfemployed, employee, and other; (4) health insurance entitlement in Indonesia, which is composed of Askes (government employees), Jamsostek (private sector employees), Kartu Sehat (insurance for the poor), other insurance, and uninsured; (5) marital status, distinguished as not married, married, and divorced/widowed; (6) area of residence, categorized as outside Java Island rural, outside Java urban, in Java rural, and in Java urban; (7) and dentist availability, categorized as less or more than 1 dentist available per 30,000 persons.

After the estimates had been obtained, the marginal effects of dental care utilization evaluated at the mean of each determinant $k\left(\beta_{k}{ }^{m}\right)$ were generated to deal with discrete changes in the context of the non-linear regression of dental care utilization, which codifies the change in predicted probability associated with a one-unit change in the explanatory variable. Then, $C$ of need-expected dental care utilization $\left(C_{N}\right)$ was computed by running Eq.1 using $\hat{y}_{i}$ and its mean, which represents the predicted average amount of dental care that an individual would have received if he or she had been treated the same as others who fall within the same age and gender groups. In the second step, $H I$ was obtained by subtracting $C_{N}$ from $C_{M}$ :

$$
H I=C_{M}-C_{N}
$$

The $H I$ is defined as the difference between the distributions of actual and estimated need-expected dental care utilization. Thus, it can be regarded as the indicator of horizontal equity in the context of providing equal treatment to those with the same need for care, even though it is merely a numerical value. A positive (negative) value for
$H I$ indicates horizontal inequity in favor of the higher (lower) SES groups, and zero indicates horizontal equity, where dental care is proportionally distributed across SES groups (Schneider and Hanson 2006).

Furthermore, this study aimed to explain why inequality in dental care utilization exists between SES groups. The decomposition method reveals to what extent inequality in dental care can be explained, for example, by inequality in insurance coverage rather than by inequality in the availability of healthcare facilities. In an attempt to describe sources of inequality in dental care use, $C$, which is equal to $C_{M}$ from Eq. 1, could also be expressed as the sum of the contributions from various determinants, represented by two main components (Wagstaff et al. 2003; Van Doorslaer et al. 2004b):

$$
C=\Sigma_{k} \eta_{k} C_{k}+G C \varepsilon / \bar{y}_{i}
$$

First, the explained component $\left(\Sigma_{k} \eta_{k} C_{k}\right)$ is the sum of the contributions of both need and non-need determinants. $\eta_{k}$ is the elasticity of dental care utilization with respect to each need and non-need determinant, which can be calculated by $\eta_{k}=\beta_{k}{ }^{m} \bar{x}_{k} / \bar{y}_{i}$. $\beta_{k}{ }^{m}$ represents the marginal effects of dental care utilization on need and non-need determinants as mentioned above. $\bar{x}_{k}$ is the mean of each determinant $k$. $C_{k}$ is the $C$ for each determinant $k$, which is calculated by using Eq. 1, replacing $y_{i}$ with $x_{k}$ and $\bar{y}_{i}$ with $\bar{x}_{k}$. If the contributions of an explanatory variable carry a negative (positive) sign, this means that the variable has the effect of reducing (increasing) inequality, favoring the lower (higher) SES groups. Second, the residual component that cannot be explained by systematic variation is represented by the latter component of Eq. $3\left(G C \varepsilon / \bar{y}_{i}\right)$, which is equal to the difference between $\mathrm{C}$ and $\left(\Sigma_{k} \eta_{k} C_{k}\right)$. Of course, the contributions of each determinant to $C$ are merely numerical estimates. However, they can be considered criteria of inequity by making a judgment as to whether or not differences in the determinants are unnecessary and avoidable, and whether or not they are considered unfair and unjust.

\section{Results}

Table 1 shows the descriptive statistics of all 730,832 adult respondents of Susenas and lists the parameters that pertain to the 20,718 subjects who reported self-assessed dental problems in the month preceding the interview. The results of the chi-square tests showed significant differences between the distributions of all adult respondents versus the group used in our analyses for all variables investigated. The distributions among our study subjects suggest associations between dental problems and relatively poorer living standards, lower educational attainment, unemployment, and enrollment in Kartu Sehat. It can be seen in the bivariate analysis that the proportion of dental care use was dominated by those in the richest quintile. Among the study subjects who reported using dental care, $41.4 \%$ were enrollees of Askes (government employee insurance), $38.6 \%$ in Jamsostek (private sector employee insurance), $34.2 \%$ in Kartu Sehat (insurance for the poor), and $24.3 \%$ were uninsured. The dental care utilization rates were $32.2 \%$ and $30.1 \%$ in urban and rural areas of Java Island, respectively, and $29.7 \%$ and $24.3 \%$ in the urban and rural areas of the other islands, respectively.

We plotted the cumulative percentage of dental care 
Table 1. Descriptive statistics of all adult respondents of Susenas 2004 compared to the subjects of study.

\begin{tabular}{|c|c|c|c|c|}
\hline \multirow[b]{2}{*}{ Variables } & \multicolumn{2}{|c|}{$\begin{array}{l}\text { All adult respondents of Susenas } \\
\qquad(N=730,832)\end{array}$} & \multicolumn{2}{|c|}{$\begin{array}{l}\text { Subjects of study } \\
\quad(N=20,718)\end{array}$} \\
\hline & $\begin{array}{l}\text { Number of } \\
\text { respondents }\end{array}$ & $(\%)$ & $\begin{array}{l}\text { Number of } \\
\text { respondents }\end{array}$ & $(\%)$ \\
\hline \multicolumn{5}{|l|}{ Dental care utilization* } \\
\hline Having dental care & 18,289 & $(2.5)$ & 7,155 & $(34.5)$ \\
\hline Having no dental care & 712,543 & $(97.5)$ & 13,563 & $(65.5)$ \\
\hline \multicolumn{5}{|l|}{ Age and gender combined (years)* } \\
\hline Female aged 15-29 & 141,750 & $(19.4)$ & 3,903 & $(18.8)$ \\
\hline Female aged 30-44 & 119,383 & $(16.3)$ & 3,887 & $(18.8)$ \\
\hline Female aged 45-59 & 67,410 & $(9.2)$ & 1,998 & $(9.6)$ \\
\hline Female aged 60 years and over & 39,263 & $(5.4)$ & 827 & $(4.0)$ \\
\hline Male aged $15-29$ & 139,475 & $(19.1)$ & 3,105 & $(15.0)$ \\
\hline Male aged 30-44 & 116,083 & $(15.9)$ & 3,522 & $(17.0)$ \\
\hline Male aged 45-59 & 71,158 & $(9.7)$ & 2,446 & $(11.8)$ \\
\hline Male aged 60 years and over & 36,310 & $(5.0)$ & 1,030 & $(5.0)$ \\
\hline \multicolumn{5}{|l|}{ Living standard* } \\
\hline 1st quintile (poorest) & 146,167 & $(20.0)$ & 4,617 & $(22.3)$ \\
\hline 2nd quintile & 146,166 & $(20.0)$ & 4,249 & $(20.5)$ \\
\hline 3rd quintile & 146,167 & $(20.0)$ & 3,919 & (18.9) \\
\hline 4th quintile & 146,167 & $(20.0)$ & 4,048 & (19.5) \\
\hline 5th quintile (richest) & 146,165 & $(20.0)$ & 3,885 & $(18.8)$ \\
\hline \multicolumn{5}{|l|}{ Educational level attainment* } \\
\hline No formal education & 62,298 & $(8.5)$ & 1,845 & $(8.9)$ \\
\hline Primary & 305,435 & $(41.8)$ & 13,595 & $(65.6)$ \\
\hline Secondary & 317,715 & $(43.5)$ & 4,321 & (20.9) \\
\hline Higher & 45,384 & $(6.2)$ & 957 & $(4.6)$ \\
\hline \multicolumn{5}{|l|}{ Working status* } \\
\hline Agriculture/fishery & 106,663 & $(14.6)$ & 3,130 & $(15.1)$ \\
\hline Self-employed & 204,613 & $(28.0)$ & 6,449 & $(31.1)$ \\
\hline Employee & 127,657 & $(17.5)$ & 2,976 & (14.4) \\
\hline Other & 291,899 & $(39.9)$ & 8,163 & (39.4) \\
\hline \multicolumn{5}{|l|}{ Health insurance entitlement* } \\
\hline Askes (government employees) & 42,634 & $(5.8)$ & 1,260 & $(6.1)$ \\
\hline Jamsostek (private sector employees) & 24,707 & (3.4) & 603 & $(2.9)$ \\
\hline Kartu Sehat (insurance for the poor) & 72,488 & (9.9) & 3,911 & (18.9) \\
\hline Other insurance & 7,522 & $(1.0)$ & 735 & $(3.5)$ \\
\hline Uninsured & 583,481 & $(79.8)$ & 14,209 & (68.6) \\
\hline \multicolumn{5}{|l|}{ Marital status* } \\
\hline Not married & 198,472 & $(27.2)$ & 4,574 & $(22.1)$ \\
\hline Married & 477,657 & $(65.4)$ & 14,857 & (71.7) \\
\hline Divorced/Widowed & 54,703 & $(7.5)$ & 1,287 & $(6.2)$ \\
\hline \multicolumn{5}{|l|}{ Geographic characteristics (residence)* } \\
\hline Outside Java rural & 329,625 & $(45.1)$ & 11,197 & $(54.0)$ \\
\hline Outside Java urban & 150,428 & $(20.6)$ & 3,682 & $(17.8)$ \\
\hline In Java rural & 118,542 & $(16.2)$ & 2,637 & $(12.7)$ \\
\hline In Java urban & 132,237 & $(18.1)$ & 3,202 & $(15.5)$ \\
\hline \multicolumn{5}{|l|}{ Dentist availability* } \\
\hline$>1$ dentist per Puskesmas (30000 prs) & 559,302 & $(76.5)$ & 13,464 & $(65.0)$ \\
\hline$<1$ dentist per Puskesmas (30000 prs) & 171,530 & $(23.5)$ & 7,254 & $(35.0)$ \\
\hline
\end{tabular}

"All adult respondents" includes both those who reported having had dental problems and those who did not.

"Subjects of study" include only those who reported having had dental problems.

$* p$-value $<0.05, \chi^{2}$ test between all adult respondents and subjects of study. 
Table 2. Distribution of dental care utilization according to living standard quintiles among adult Susenas respondents who perceived need for dental care in Indonesia 2004.

\begin{tabular}{lcccccr}
\hline $\begin{array}{c}\text { Living } \\
\text { standard } \\
\text { quintiles }\end{array}$ & $\begin{array}{c}\text { No. of } \\
\text { respondents }\end{array}$ & $\begin{array}{c}\text { Relative } \% \\
\text { respondents }\end{array}$ & $\begin{array}{c}\text { Cumulative } \% \\
\text { respondents } \\
(x \text {-axis })\end{array}$ & $\begin{array}{c}\text { No. of } \\
\text { dental care } \\
\text { utilization }\end{array}$ & $\begin{array}{c}\text { Relative \% } \\
\text { dental care } \\
\text { utilization }\end{array}$ & $\begin{array}{c}\text { Cumulative } \% \\
\text { dental care } \\
\text { utilization }(y \text {-axis })\end{array}$ \\
\hline Poorest & 4,617 & $22.30 \%$ & $22.30 \%$ & 1,429 & $20.00 \%$ & $20.00 \%$ \\
2nd & 4,249 & $20.50 \%$ & $42.80 \%$ & 1,417 & $19.80 \%$ & $39.80 \%$ \\
3rd & 3,919 & $18.90 \%$ & $61.70 \%$ & 1,345 & $18.80 \%$ & $58.60 \%$ \\
4th & 4,048 & $19.50 \%$ & $81.20 \%$ & 1,356 & $19.00 \%$ & $77.50 \%$ \\
Richest & 3,885 & $18.80 \%$ & $100.00 \%$ & 1,608 & $22.50 \%$ & $100.00 \%$ \\
Total & 20,718 & & & 7,155 & & \\
\hline
\end{tabular}

utilization within a one-month recall period, as reported by respondents ( $y$-axis), against the cumulative percentage of the sample ranked by equivalent adult household consumption ( $x$-axis), beginning with the poorest and ending with the richest (Table 2). If everyone, irrespective of his or her living standards, had exactly the same level of dental care utilization, the concentration curve would be a $45^{\circ}$ line, running from the bottom left-hand corner to the top right-hand corner. This is known as the line of equality. The farther the concentration curve lies from the line of equality, the greater the degree of inequality in dental care across the SES groups (Wagstaff et al. 2003; Van Doorslaer and Jones 2003; O'Donnell et al. 2008). The concentration curve of the actual dental care utilization among the study sample (CC1) lay slightly below the line of equality, indicating that there was a slightly pro-rich inequality with respect to dental care utilization in Indonesia (Fig. 1). The concentration curve of actual dental care utilization among all adult Susenas respondents (CC2) lay slightly below CC1, and the concentration curve of need-expected dental care utilization (CC3) lay nearer to the line of equality.

In addition, we used the concentration index $(C)$ to observe the significance of any inequality as well as when the concentration curves crossed or where a numerical measure of inequality in the use of dental care was required. This is defined as twice the area between the concentration curve and the line of equality. It lies in the range of -1 to +1 , with a negative (positive) value when the concentration curve lies above (below) the line of equality, which represents inequality in favor of groups with lower (higher) living standards. Zero indicates that there is no inequality, such that everyone receives the same amount of dental care (Morris et al. 2005; Van Doorslaer et al. 2008). Although the concentration curve of actual dental care utilization shows only a slight difference from the line of equality, the $C$ of actual dental care utilization $\left(C_{M}\right)$ was statistically significant after it was analyzed with Eq. 1. $C_{M}$ was 0.064 , meaning that actual dental care use was significantly more concentrated among higher SES groups (Table 3). The $C$ of need-expected dental care utilization $\left(C_{N}\right)$ was -0.003 , illustrating that overall dental care should be pro-poor, because the need for dental care as a proxy was more concentrated among the lower SES groups. This result was supported by the concentration curves (Fig. 1). When the need for dental care was standardized $(H I)$, it was even more pro-rich than the actual dental care utilization $\left(C_{M}\right)$, which means that there was significant horizontal inequity in the distribution of dental care utilization in favor of the higher SES groups, as expressed by the positive indices $(H I=0.066)$. Compared to other quintiles, the highest SES quintile received more dental care $(0.414)$ than was believed to be needed (0.339), and the situation was even more pro-rich when need was standardized (0.419).

Table 3 demonstrates the decomposition results according to the marginal effects $\left(\beta_{k}{ }^{m}\right)$, the concentration index for each determinant $\left(C_{k}\right)$ and the contributions of the determinants to overall $C\left(C_{M}\right)$. Marginal effects $\left(\beta_{k}{ }^{m}\right)$ were interpreted as follows: increasing age was associated with increasing dental care utilization; female respondents tended to use dental care more than males; dental care was significantly more common among the highest SES quintile, welleducated people, those covered by health insurance, and those residing on the island of Java. In contrast, employed respondents reported significantly less utilization of dental care. $C_{k}$ should be interpreted as follows: females and males of working age (30-44 years), who may be more financially independent, were more concentrated in higher SES groups than individuals of other ages (Van Doorslaer and Koolman 2004a). A socioeconomic inequality gradient can be observed where the concentration indices range from $C_{k}=-0.384$ followed by $0.006,0.415$, and 0.860 for the highest quintile. The increasing values of the concentration indices in accordance with wealth were an expected result. We also noted a socioeconomic gradient in education and insurance participation. Those with a higher level of education and those insured with Jamsostek were concentrated in the richer quintiles. Those who lived in Java Island's rural areas were socioeconomically disadvantaged.

The main contributing factors through which inequitable distributions of dental care utilization arise were inequality in the highest quintile $(0.038)$, followed by residence in urban Java Island (0.015) and participation in the Askes program (0.012). Contributions of the determinants to the overall inequality of dental care utilization should be interpreted as follows: the marginal effect $\left(\beta_{k}{ }^{m}\right)$ of respondents with the highest education level was significant, mea- 


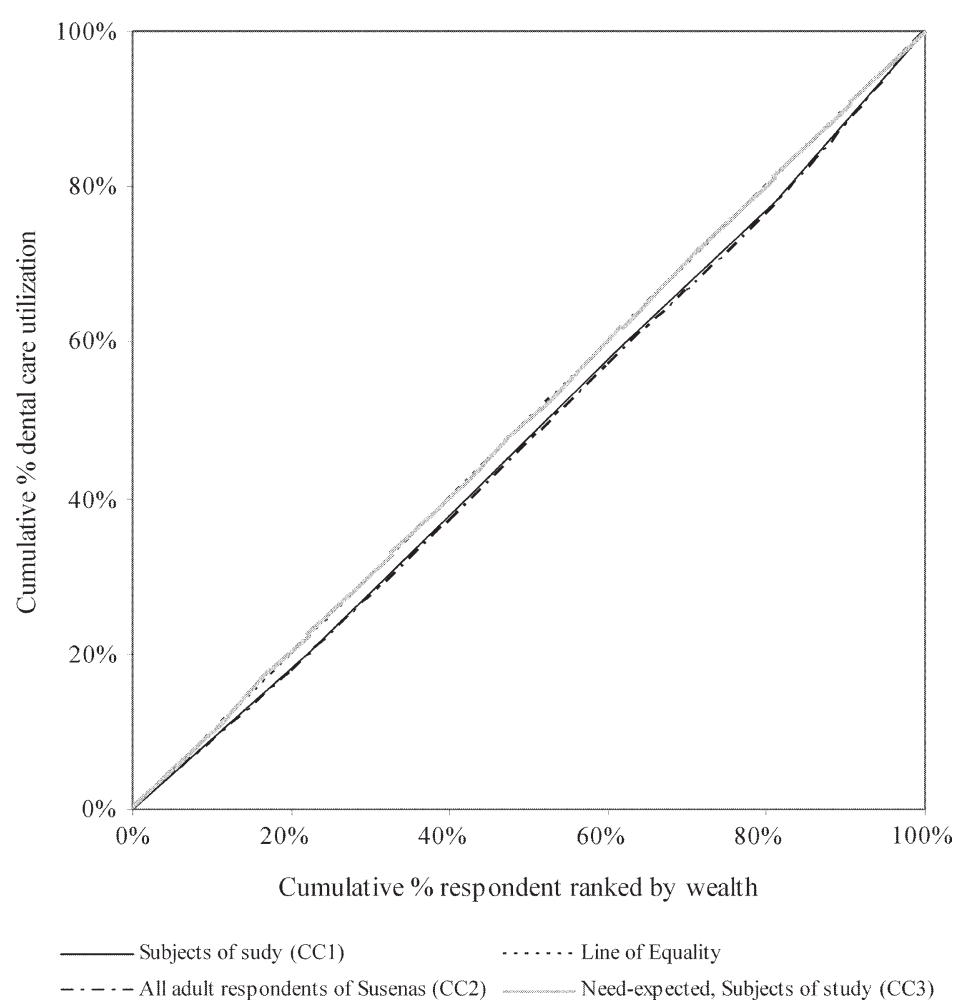

Fig. 1. Concentration Curves for dental care utilization, Indonesia 2004.

Table 3. Distribution of actual, need-expected and need-standardized dental care utilization according to living standard quintiles, Indonesia 2004.

\begin{tabular}{lccc}
\hline \multicolumn{1}{c}{$\begin{array}{c}\text { Living standard } \\
\text { quintiles }\end{array}$} & $\begin{array}{c}\text { Actual dental care } \\
\text { utilization }\left(y_{i}\right)\end{array}$ & $\begin{array}{c}\text { Need-expected dental } \\
\text { care utilization }\left(\hat{y}_{i}\right)\end{array}$ & $\begin{array}{c}\text { Need-standardized dental } \\
\text { care utilization }\left(\hat{y}_{i}^{I S}\right)\end{array}$ \\
\hline Poorest & 0.310 & 0.345 & 0.309 \\
2nd quintile & 0.334 & 0.346 & 0.331 \\
3rd quintile & 0.343 & 0.345 & 0.341 \\
4th quintile & 0.335 & 0.343 & 0.336 \\
Richest & 0.414 & 0.339 & 0.419 \\
Mean & 0.345 & 0.344 & 0.345 \\
$\mathrm{C}_{\mathrm{M}}$ / $\mathrm{C}_{\mathrm{N}}$ /HI & $\mathbf{0 . 0 6 4}$ & $\mathbf{- 0 . 0 0 3}$ & $\mathbf{0 . 0 6 6}$ \\
Standard Error & 0.007 & 0.001 & 0.007 \\
95\% Conf. interval & $0.049,0.078$ & $-0.004,-0.002$ & $0.052,0.081$ \\
\hline
\end{tabular}

Bold values indicate statistically significant parameters at $p$ value $<0.05$.

suring 0.109 at the mean. This indicates that the probability of dental care utilization was 10.9 percentage points more for this group than among the respondents with no formal education. The value of the marginal effect $(0.109)$ is equivalent to 0.015 of the elasticity at the mean $\left(\eta_{k}=\beta_{k}{ }^{m} \bar{x}_{i} /\right.$ $\left.\bar{y}_{i}\right)$. The positive concentration index $\left(C_{k}=0.586\right)$ means that the respondents with the highest education level were disproportionately concentrated in higher SES groups, thus contributing $0.9 \%$ to the total observed dental care utilization inequality $\left(\eta_{k} C_{k}=0.009\right)$. As this has the same sign as the overall $C$ (positive $C_{M}$ ), which indicated that actual dental care was concentrated among higher SES groups, it implies that well-educated respondents were a reservoir of the wealthier individuals who reported dental care utilization. Interpretations of contributions to $C$ with the opposite sign can be described as follows: respondents who were covered by Kartu Sehat had a relatively high probability of using dental care $\left(\beta_{k}{ }^{m}=0.067\right)$, but because they were disproportionately concentrated in lower SES groups $\left(C_{k}=\right.$ $-0.146)$, their contribution of $-0.5 \%\left(\eta_{k} C_{k}=-0.005\right)$ was in a direction opposite to the overall inequality observed. In the same way, the employee groups were respondents who were concentrated in higher SES categories $\left(C_{k}=0.183\right)$. However, they had a low probability of dental care utiliza- 
tion $\left(\beta_{k}{ }^{m}=-0.196\right)$, causing a negative contribution $\left(\eta_{k} C_{k}=\right.$ $-0.015)$ that tended to narrow the inequality slightly.

\section{Discussion}

The concentration curves of dental care use were unexpectedly very close to the line of equality (Fig. 1). This may have been caused by potential biases. First, the Susenas assessed dental care need through a measure of self-assessed dental health. This might have caused biased results if individuals across socio-economic groups differentially perceived their health and/or had different expectations regarding their health (WHO 2005). Poor people may have perceived their health status as less severe than those who were better off, mainly because they did not have the luxury of letting ill health compromise their daily work (Goddard and Smith 2001). However, some demonstrated that self-assessment indicators have been effective in capturing health variation in a population (Locker and Jokovic 1996; Heft et al. 2003; O’Donnell et al. 2007). Another potential bias may arise from the relatively short reference period for reported dental care utilization by Susenas, which used a one-month recall period of self-assessed dental care needs, reflecting the period when the survey was conducted. Naturally, these data do not lend themselves to annual interpretation. This assessment may have limited the validity of the outcome variable, but such a short reference period would also have reduced recall bias. The direction of these two types of biases would most likely understate the degree of inequality in dental care use among SES groups (Schneider and Hanson 2006).

This study included individuals who reported a need for dental care, with the purpose to describe the population who would most likely benefit from dental treatment, since those who experience no perceived need may not demand dental treatment. It may be more important to identify those for whom health services will produce the most health gain (Locker and Jokovic 1996). Nonetheless, a selection bias may be present due to the limitations of our database, and descriptive statistics give some insight regarding this potential bias (Table 1). For example, the higher proportion of poor individuals within our sample may have overemphasized inequality in dental care utilization, since the poor received less dental care. The higher rate of residence in areas of poor dentist availability might also have made the inequality appear larger. By contrast, a higher proportion of Kartu Sehat enrollees in our sample may have lessened the appearance of inequality. It is worthwhile to point out that the interaction of all of the potential biases may neutralize the results.

This study employed the concentration index for several reasons: (1) it reflects the socioeconomic dimension to inequalities in health; (2) it reflects the experiences of the entire population; (3) it is sensitive to changes in the distribution of the population across socioeconomic groups; (4) its visual representation by means of the concentration curve; (5) and the ease with which it can be decomposed
(Wagstaff et al. 1991; Erreygers 2009a). Nonetheless, there is still some controversy in the literature regarding which disparity indices meet the most ideal properties (Clarke et al. 2002; Erreygers 2009a, b; Wagstaff 2009). Concern also emerged as to how changes in the prevalence of the health variable being measured may affect the disparity estimates (Scanlan 2006; Cheng et al. 2008). Furthermore, prior research has called attention to potential biases involved in standardization procedures, by which the $C$ of the needexpected concentration index $\left(C_{N}\right)$ and the horizontal inequity index $(H I)$ were computed. These authors suggest that bootstrapping methods may correct for biased estimates and underestimated standard errors in the procedures (Van Doorslaer and Koolman 2004a). To solve these methodological problems, further research is necessary.

Despite these limitations, our finding that the concentration curves lay below the line of equality supports the existence of pro-rich inequality in dental care utilization (Fig. 1). This and the other findings from this study have health policy implications for Indonesia and other developing countries. If the government aims to improve access to dental care, especially for the poor, as a part of realizing fair and just healthcare, then horizontal equity must be ensured by eliminating out-of-pocket payments for dental care. In Indonesia, this could be addressed by increasing Kartu Sehat enrollment. Moreover, the concentration curve and $H I$ indicate that dental care utilization is more dependent upon the ability to pay than on actual need. It could be the case that the poor chose not to use dental care, because they feared that paying for dental care might limit their ability to purchase other goods and services. Affordability is typically a major reason for the underutilization of dental care among these groups (Wu 2007; O'Donnell et al. 2008). Income itself contributes to the pro-rich inequality here, suggesting that income remains a major factor in dental care utilization. In other words, unmet need was concentrated in lower SES groups in the sense of inequity. This is a significant finding, but it is not surprising in a system where high dental care costs are mostly covered by out-of-pocket payments (Petersen 2003; WHO 2005). This finding is consistent with those of other studies (Van Doorslaer 2008; Somkotra and Detsomboonrat 2008).

This study illustrated inequality by calculating the concentration index of actual dental care utilization $\left(C_{M}\right)$. However, we also calculated inequity in terms of the horizontal inequity index $(H I)$, which took into account the concentration index of need-expected dental care utilization $\left(C_{N}\right)$ with respect to its moral and ethical dimensions. In this study, need-expected dental care utilization $\left(\hat{y}_{i}\right)$ was estimated using both need and non-need determinants $\left(x_{k}\right)$. Although $\hat{y}_{i}$ was not a measurable value (e.g., prevalence of caries), previous studies have reported that $\hat{y}_{i}$ may reflect actual dental care need (Van Doorslaer and Jones 2003; Morris et al. 2005). $\hat{y}_{i}$ values, from the poorest to the fourth quintile, were higher than the actual dental care utilization $\left(y_{i}\right)$, meaning that the lower SES groups generally exhibited 
poorer dental health and therefore were in greater need of dental care (Table 3). The variables used as proxies for need determinants were standardized age and gender categories, based on the correlation with SES and health (O'Donnell et al. 2007). The combination of age and gender has been reported to be a reliable proxy to dental care need (Lin and Schwarz 2001; Nguyen and Häkkinen 2004; Bryant et al. 2009). Based on SKRT 2004, females have a higher prevalence of dental problems than men and have a higher unmet need for dental care. Nonetheless, potential bias may occur for omitted variables in the $H I$ measurement (O’Donnell et al. 2007; Bago d'Uva et al. 2009).

The decomposition method clarified the demographic, socioeconomic, and geographic sources of dental care utilization inequality (Table 4). We observed from the marginal effects that increasing age was correlated with increasing probability of dental care utilization. This tendency might be due to the biological process of aging, which causes degeneration (Petersen 2003). Based on SKRT 2004, females tended to use dental care more than males, which could be because women tend to be more concerned about their health and aesthetic qualities than men are, but also because the prevalence of caries in women is higher than in men. Individuals who had attained higher educational levels, who most likely belonged to the higher SES quintiles, might have been better informed about dental health options and may have chosen to undergo regular dental check-ups, resulting in higher dental care use than individuals with a lower level of education (Fisher-Owens et al. 2008). Surprisingly, employees reported lower dental care utilization, which might reflect a high opportunity cost to negotiating time off from work.

In addition, the decomposition method showed that the highest living standard, residing in urban Java, and enrollment in Askes were significant contributors to pro-rich inequality in dental care utilization. In contrast to the unavoidable biological attributes of age and gender, these determinants were considered unnecessary and avoidable sources of inequality in dental care utilization, which might arouse inequity, a sense of unfairness and unjustness, but could be eliminated by proper health policy. The highest living standard was naturally the most important contributing factor to the unequal distribution of dental care utilization among SES groups, since the living standard was the primary indicator of the SES in this study; such a difference is considered unjust. In other words, living standard differences by socio-economic status demonstrate inequity. The results also indicated that health insurance is a significant source of inequality. Therefore, our data suggest that being covered by health insurance reduces economic barriers to accessing dental care. This, in turn, encourages people to use dental care services (Somkotra and Detsomboonrat 2008). This result highlights that the avoidable insufficiency of health insurance coverage remains an important barrier to dental care.

As geographic characteristics were the other significant source of inequality, attention should be focused on geographic barriers in addition to economic barriers (FisherOwens et al. 2008; Van Doorslaer et al. 2006). Based on data from Indonesia's $\mathrm{MOH}, 77.0 \%$ of dentists are women, and they tend to live in urban areas with their families. Naturally, dentists are concentrated on Java Island, and they might not be as available in rural areas and in other provinces. Indeed, based on the Indonesian Medical Council data in 2004, there were 2.9 dentists per 30,000 individuals on Java Island and only 1.6 on the other islands. Community health centers (Puskesmas), which are public facilities located in every sub-district, assume significant roles in improving dental health in their regions by promoting, preventing, and providing low-cost simple curative dental care (Kristiansen and Santoso 2006). Each Puskesmas should serve 30,000 citizens at most. Nevertheless, as there is an insufficient number of dentists with an unequal distribution, many Puskesmas facilities do not provide dental services, resulting in a high number of untreated dental caries (Thabrany 2006). As one of the important issues highlighted in this article is the avoidable insufficiency and unevenness of the dentists' distribution, one possible solution could be to constantly deploy recently graduated dentists to remote districts as mandatory service, and thus ensure dentist availability at most Puskesmas (Kristiansen and Santoso 2006). Moreover, it is important that dental health resource distribution is based on the need for dental care to help reduce inequity in dental care. To help meet the need for dental health professionals, the government should help dental schools increase the supply of qualified dentists. The estimated number of dental health professionals should reflect both the actual demand and the desired population ratios (Thabrany 2006).

Although self-reported dental problems experienced in the month preceding the survey might not adequately estimate the real need for dental care, the nationally representative survey data is invaluable. It was used in this study to obtain the large sample size, which could not be available if dental professionals examined each individual. In a time of limited resources, as is currently the case in Indonesia, the use of subjective indicators as screening instruments provided by the Susenas data provides a rapid and inexpensive way to annually evaluate dental care in Indonesia. However, skepticism might arise regarding the near-perfect concentration curve for dental care utilization in Indonesia, meaning that various socio-economic groups have almost the same access to treatment by professional dentists. Geographic and economic barriers to dental treatment that result in a high percentage of untreated dental problems were previously reported in Indonesia. Morgan et al. (1992) indicated a widespread need for dental care in children, but dental treatment was not commonly available, especially in the rural areas of Indonesia. Recently, Sudiono (2008) reported a low demand for professional dental care among the elderly with poor dental health because of a lack of financial resources. Thereby, despite the advantages of 
Table 4. Decomposition of inequality in dental care utilization within subjects of study, Indonesia 2004.

\begin{tabular}{|c|c|c|c|c|c|c|}
\hline Need and non-need determinants $\left(x_{k}\right)$ & $\begin{array}{l}\text { Marginal effects } \\
\qquad\left(\beta_{k}^{m}\right)\end{array}$ & $95 \% C I$ & $\begin{array}{c}\text { Mean } \\
\left(\bar{x}_{k}\right)\end{array}$ & $\begin{array}{l}\text { Elasticity } \\
\qquad\left(\eta_{k}\right)\end{array}$ & $C_{k}$ & $\begin{array}{l}\text { Contributions to } C \\
\qquad\left(\eta_{k} C_{k}\right)\end{array}$ \\
\hline \multicolumn{7}{|c|}{ Actual dental care use $\left(\bar{y}_{i}=0.345 \& C_{M}=0.064\right)$} \\
\hline \multicolumn{7}{|l|}{ Age and gender combined (years) } \\
\hline Female aged $30-44$ & 0.195 & $-0.01,0.05$ & 0.187 & 0.106 & 0.036 & 0.004 \\
\hline Female aged 45-59 & 0.462 & $0.01,0.09$ & 0.096 & 0.129 & -0.025 & -0.003 \\
\hline Female aged 60 years and over & 0.472 & $-0.01,0.10$ & 0.040 & 0.055 & -0.002 & -0.000 \\
\hline Male aged $15-29$ & -0.022 & $-0.06,-0.01$ & 0.150 & -0.010 & -0.059 & 0.001 \\
\hline Male aged $30-44$ & -0.038 & $-0.07,-0.01$ & 0.170 & -0.019 & 0.050 & -0.001 \\
\hline Male aged 45-59 & 0.050 & $0.01,0.09$ & 0.118 & 0.017 & -0.018 & -0.000 \\
\hline Male aged 60 years and over & 0.090 & $0.04,0.14$ & 0.050 & 0.013 & -0.016 & -0.000 \\
\hline \multicolumn{7}{|l|}{ Living standard } \\
\hline 2nd quintile & 0.008 & $-0.02,0.04$ & 0.205 & 0.005 & -0.384 & -0.002 \\
\hline 3rd quintile & 0.138 & $-0.02,0.04$ & 0.189 & 0.076 & 0.006 & 0.000 \\
\hline 4th quintile & 0.026 & $-0.01,0.06$ & 0.195 & 0.014 & 0.415 & 0.006 \\
\hline 5th quintile (richest) & 0.082 & $0.05,0.11$ & 0.187 & 0.045 & 0.860 & 0.038 \\
\hline \multicolumn{7}{|l|}{ Educational level attainment } \\
\hline Primary & 0.213 & $-0.01,0.05$ & 0.656 & 0.404 & -0.059 & -0.024 \\
\hline Secondary & 0.024 & $-0.02,0.06$ & 0.209 & 0.014 & 0.174 & 0.002 \\
\hline Higher & 0.109 & $0.05,0.17$ & 0.046 & 0.015 & 0.586 & 0.009 \\
\hline \multicolumn{7}{|l|}{ Working status } \\
\hline Agriculture/fishery & -0.003 & $-0.03,0.03$ & 0.151 & -0.001 & -0.182 & 0.000 \\
\hline Self-employed & 0.011 & $-0.02,0.04$ & 0.311 & 0.010 & -0.009 & -0.000 \\
\hline Employee & -0.196 & $-0.05,0.01$ & 0.144 & -0.082 & 0.183 & -0.015 \\
\hline \multicolumn{7}{|l|}{ Health insurance entitlement } \\
\hline $\begin{array}{l}\text { Askes } \\
\text { (government employee insurance) }\end{array}$ & 0.179 & $0.14,0.22$ & 0.061 & 0.032 & 0.377 & 0.012 \\
\hline $\begin{array}{l}\text { Jamsostek } \\
\text { (private sector employee insurance) }\end{array}$ & 0.090 & $0.04,0.15$ & 0.029 & 0.008 & 0.672 & 0.005 \\
\hline $\begin{array}{l}\text { Kartu Sehat } \\
\text { (insurance for the poor) }\end{array}$ & 0.067 & $0.04,0.09$ & 0.189 & 0.037 & -0.146 & -0.005 \\
\hline Other insurance & 0.224 & $0.17,0.28$ & 0.035 & 0.023 & -0.167 & -0.004 \\
\hline \multicolumn{7}{|l|}{ Marital status } \\
\hline Married & 0.014 & $-0.02,0.04$ & 0.717 & 0.029 & 0.020 & 0.001 \\
\hline Divorced/Widowed & 0.025 & $-0.03,0.08$ & 0.062 & 0.004 & 0.045 & 0.000 \\
\hline \multicolumn{7}{|l|}{ Geographic characteristics (residence) } \\
\hline Outside Java urban & 0.004 & $-0.02,0.03$ & 0.178 & 0.002 & 0.165 & 0.000 \\
\hline In Java rural & 0.050 & $0.02,0.08$ & 0.127 & 0.018 & -0.314 & -0.006 \\
\hline In Java urban & 0.082 & $0.06,0.11$ & 0.154 & 0.037 & 0.423 & 0.015 \\
\hline \multicolumn{7}{|l|}{ Dentist availability } \\
\hline$>1$ dentist per Puskesmas (30000prs) & -0.058 & $-0.08,-0.04$ & 0.650 & -0.109 & 0.115 & -0.013 \\
\hline Total explained contributions $\left(\Sigma_{k} \eta_{k} C_{k}\right)$ & & & & & & 0.021 \\
\hline Residual (unexplained) $G C \varepsilon / \bar{y}_{i}$ & & & & & & 0.042 \\
\hline
\end{tabular}

Reference categories (Age and gender combined = female aged 15-29 years, Living standard = poorest, Educational level attainment $=$ no formal education, Working status $=$ other, Health insurance entitlement $=$ uninsured, Marital status $=$ not married, Residence $=$ outside Java rural, dentist availability $=<1$ dentist per Puskesmas); bold values indicate statistically significant parameters at $p<0.05 ; C I=$ Confidence interval. 
using a large-scale secondary data set, caution with an eye toward the potential biases described above is warranted. Further research is encouraged to analyze both secondary and primary observations data.

\section{Conclusions}

This study analyzed dental care utilization among Indonesian people with a perceived need for dental care. The results may have limited generalizability to Indonesia's dental care utilization overall. The concentration curve indicated a slight inequality in dental care utilization, skewed toward the wealthier respondents. The concentration index showed significantly higher dental care utilization among higher SES groups. The horizontal inequity index illustrated higher unmet needs for dental care among lower SES groups, and the decomposition revealed that higher SES, urban Java Island residency, and insurance coverage contributed significantly to inequality in dental care utilization. The higher unmet needs for dental care in lower SES populations reflect the nature of an unfair and unjust health system in Indonesia. The differences in dental care utilization between lower and higher SES groups are unnecessary and avoidable if targeted policies are successfully introduced. To eliminate such unfairness in the system, expanding health insurance coverage to include basic dental care would reduce Indonesian citizens' economic barriers to dental care. In addition, a regionally equal distribution of dentists would reduce the geographic barriers to dental care. However, because of the lack of information about how dental care inequities have changed over time, we were unable to dynamically assess the effects of government policies in this study, particularly whether these policies were leading toward or away from greater social justice. Finally, the statistical analyses in this study did reveal that equity in dental care utilization in Indonesia had not been achieved as of 2004.

\section{Acknowledgments}

We would like to thank Prof. Koichi Kawabuchi, Isao Igarashi, DDS, Dr. Mardiati Nadjib, MSc, DDS, and the anonymous reviewers for providing us with helpful comments on the drafts of this manuscript.

\section{References}

Bago d'Uva, T., Jones, A.M. \& Van Doorslaer, E. (2009) Measurement of horizontal inequity in health care utilization using European panel data. J. Health Econ., 28, 280-289.

BPS (Statistics-Indonesia). (2002) National Socio-Economic Survey (Susenas) Work Manual Head of Provincial and Regency/ Municipality Statistics Office, BPS, Jakarta, Indonesia.

Braveman, P. (2006) Health disparities and health equity concepts and measurement. Annu. Rev. Public Health, 27, 167-194.

Bryant, T., Leaver, C. \& Dunn, J. (2009) Unmet healthcare need, gender, and health inequalities in Canada. Health Policy. 91, 24-32.

Cheng, N.F., Han, P.Z. \& Gansky, S.A. (2008) Methods and software for estimating health disparities: the case of children's oral health. Am. J. Epidemiol., 168, 906-914.

Clarke, P.M., Gerdtham, U.G., Johannesson, M., Bingefors, K. \&
Smith, L. (2002) On the measurement of relative and absolute income-related health inequality. Soc. Sci. Med., 55, 19231928.

Deaton, A. (1997) The Analysis of Household Survey. A Microeconometric Approach to Development Policy, 1st ed., The Johns Hopkins University Press, Baltimore, MD.

Erreygers, G. (2009a) Correcting the concentration index. $J$. Health Econ., 28, 504-515.

Erreygers, G. (2009b) Correcting the concentration index: a reply to Wagstaff. J. Health Econ., 28, 521-524.

Fisher-Owens, S.A., Barker, J.C., Adams, S., Chung, L.H., Gansky, S.A., Hyde, S. \& Weintraub, J.A. (2008) Giving policy some teeth: routes to reducing disparities in oral health. Health Aff., 27, 404-412.

Goddard, M. \& Smith, P. (2001) Equity of access to healthcare services: Theory and evidence from the UK. Soc. Sci. Med., 53, 1149-1162.

Heft, M.W., Gilbert, G.H., Shelton, B.J. \& Duncan, R.P. (2003) Relationship of dental status, socio demographic status, and oral symptoms to perceived need for dental care. Community Dent. Oral Epidemiol., 31, 351-360.

Hidayat, B., Thabrany, H., Dong, H. \& Sauerborn, R. (2004) The effects of mandatory health insurance on equity in access to outpatient care in Indonesia. Health Policy Plan., 19, 322-335.

Kawachi, I., Subramanian, S.V. \& Almeida-Filho, N. (2002) A glossary for health inequalities. J. Epidemiol. Community Health, 56, 647-652.

Kristiansen, S. \& Santoso, P. (2006) Surviving decentralization? Impacts of regional autonomy on health service provision in Indonesia. Health Policy, 77, 247-259.

Lin, H.C. \& Schwarz, E. (2001) Oral health and dental care in modern-day China. Community Dent. Oral Epidemiol., 29, 319-328.

Locker, D. \& Jokovic, A. (1996) Using subjective oral health status indicators to screen for dental care needs in older adults. Community Dent. Oral Epidemiol., 24, 398-402.

Lu, J.R., Leung, G.M., Kwon, S., Tin, K.Y.K., Van Doorslaer, E. \& O'Donnell, O. (2007) Horizontal equity in healthcare utilization evidence from three high-income Asian economies. Soc. Sci. Med., 64, 199-212.

Morgan, M.V., Wright, F.A., Matram, Z.N., Sundoro, E. \& Chester, R.K. (1992) The oral health status and health behavior of 12 and 15 year-old adolescents in Jakarta, Indonesia. Community Dent. Health, 9, 171-179.

Morris, S., Sutton, M. \& Gravelle, H. (2005) Inequity and inequality in the use of healthcare in England: an empirical investigation. Soc. Sci. Med., 60, 1251-1266.

Nguyen, L. \& Häkkinen, U. (2004) Income-related inequality in the use of dental services in Finland. Appl. Health Econ. Health Policy, 3, 251-262.

O’Donnell, O., Van Doorslaer, E., Rannan-Eliya, R.P., Somanathan, A., Adhikari, S.R., Akkazieva, B., Harbianto, D., Garg, C.C., Hanvoravongchai, P., Herrin, A.N., Huq, M.N., Ibragimova, S., Karan, A., Kwon, S., Leung, G.M., Lu, J.R., Ohkusa, Y., Pande, B.R., Racelis, R., Tin, K., Tisayaticom, K., Trisnantoro, L., Wan, Q., Yang, B. \& Zhao, Y. (2008) Who pays for healthcare in Asia? J. Health Econ., 27, 460-475.

O’Donnell, O., Van Doorslaer, E., Wagstaff, A. \& Lindelow, M. (2007) Analyzing Health Equity Using Household Survey Data: A Guide To Techniques And Their Implementation, World Bank Institute Learning Resources Series, Washington D.C.

Ohkusa, Y. \& Honda, C. (2003) Horizontal inequity in healthcare utilization in Japan. Health Care Manag. Sci., 6, 189-196.

Petersen, P.E. (2003) The World Oral Health Report 2003: continuous improvement of oral health in the $21^{\text {st }}$ century - the approach of the WHO global oral health programme. Соттиnity Dent. Oral Epidemiol., 31, 3-23.

Scanlan, J.P. (2006) Can we actually measure health disparities? 
Chance, 19, 47-51.

Schneider, P. \& Hanson, K. (2006) Horizontal equity in utilization of care and fairness of health financing: a comparison of micro-health insurance and user fees in Rwanda. Health Econ., 15, 19-31.

Somkotra, T. \& Detsomboonrat, P. (2008) Is there equity in oral healthcare utilization: experience after achieving Universal Coverage. Community Dent. Oral Epidemiol., 37, 85-96.

Sudiono, J. (2008) The features of degenerative diseases and their association with the loss of teeth in the elderly of east Jakarta (Indonesia). Southeast Asian J. Trop. Med. Public Health. 39, 184-189.

Thabrany, H. (2006) Human resources in decentralized health systems in Indonesia: Challenges for Equity. Regional Health Forum WHO South-East Asia Region, 10, 75-88.

Van Doorslaer, E., Clarke, P., Savage, E. \& Hall, J. (2008) Horizontal inequities in Australia's mixed public/private healthcare system. Health Policy, 86, 97-108.

Van Doorslaer, E. \& Jones, A.M. (2003) Inequalities in self-reported health: validation of a new approach to measurement. $J$. Health Econ., 22, 61-87.

Van Doorslaer, E. \& Koolman, X. (2004a) Explaining the differences in income-related health inequalities across European countries. Health Econ., 13, 609-628.

Van Doorslaer, E., Koolman, X. \& Jones, A.M. (2004b) Explaining income-related inequalities in doctor utilization in Europe. Health Econ., 13, 629-647.

Van Doorslaer, E., Masseria, C. \& Koolman, X. (2006) Inequalities in access to medical care by income in developed coun- tries. C. M. A. J., 174, 177-183.

Van Doorslaer, E., Wagstaff, A., Van der Burg, H., Christiansen, T., De Graeve, D., Duchesne, I., Gerdtham, U., Gerfin, M., Geurts, J., Gross, L., Häkkinen, U., John, J., Klavus, J., Leu, R.E., Nolan, B., O’Donnell, O., Propper, C., Puffer, F., Schellhorn, M., Sundberg, G. \& Winkelhake, O. (2000) Equity in the delivery of healthcare in Europe and the US. $J$. Health Econ., 19, 553-583.

Wagstaff, A. (2009) Correcting the concentration index: a comment. J. Health Econ., 28, 516-520.

Wagstaff, A., Paci, P. \& Van Doorslaer, E. (1991) On the measurement of inequalities in health. Soc. Sci. Med., 33, 545-557.

Wagstaff, A., Van Doorslaer, E. \& Watanabe, N. (2003) On decomposing the causes of health sector inequalities with an application to malnutrition inequalities in Vietnam. J. Econometrics, 112, 207-223.

Whitehead, M. (1992) The Concepts and Principles of Equity and Health. Int. J. Health Serv., 22, 429-445.

WHO Regional Office for the Western Pacific \& WHO Regional Office for South-East Asia (2005) Social Health InsuranceSelected Case Studies from Asia and The Pacific. WHO.

$\mathrm{Wu}$, B. (2007) Dental service utilization among urban and rural older adults in China - A brief communication. J. Public Health Dent., 67, 185-188.

Yiengprugsawan, V., Lim, L.L.Y., Carmichael, G.A., Sidorenko, A. \& Sleigh, A.C. (2007) Measuring and decomposing inequity in self-morbidity and self-assessed health in Thailand. International Journal for Equity in Health, 6, 23. 